American Journal of

Health, Medicine and Nursing Practice (AJHMN)
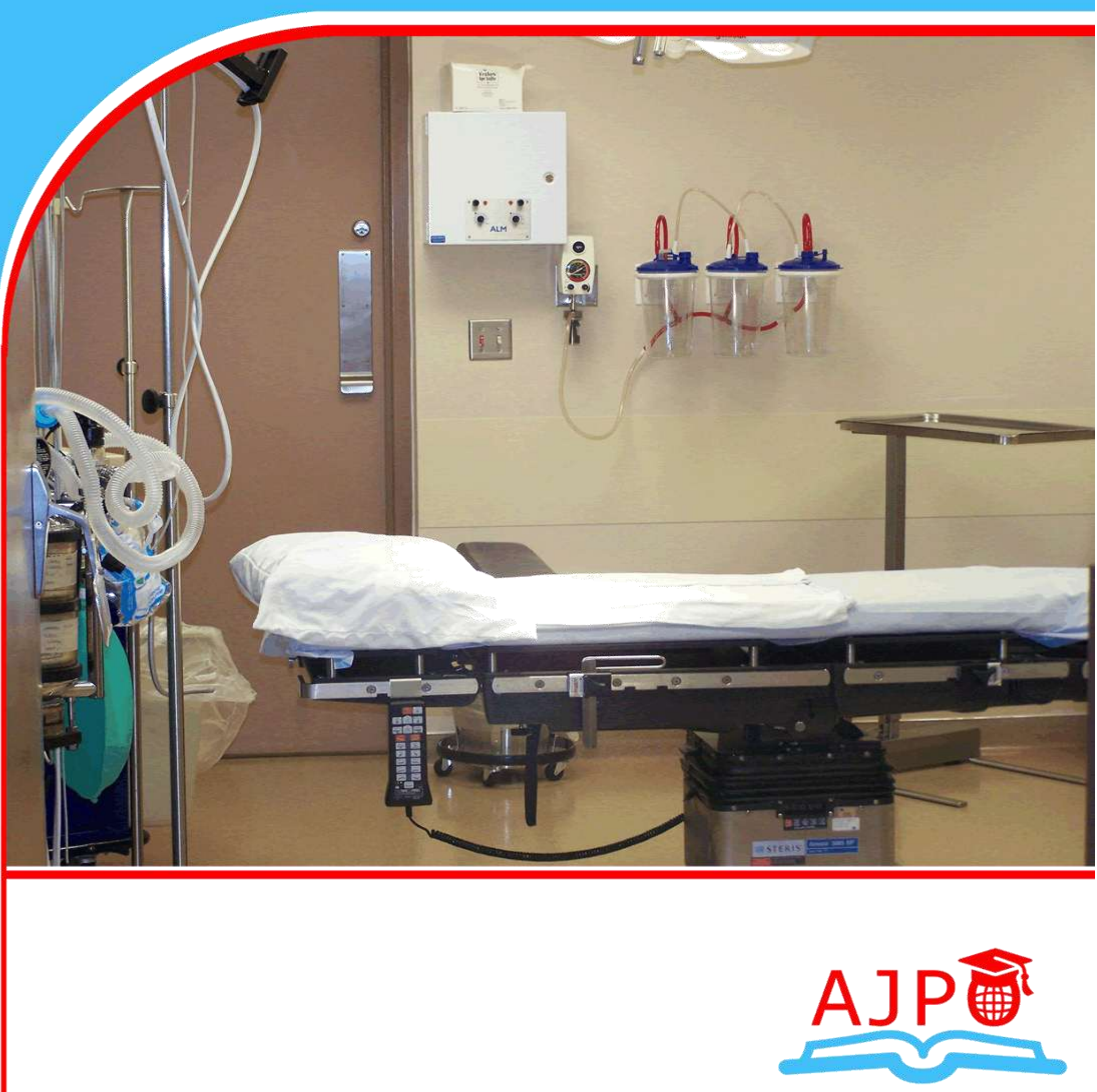
American Journal of Health, Medicine and Nursing Practice

ISSN 2520-4017 (Online)

Vol.6, Issue 3, pp 25 - 38, 2021

www.ajpojournals.org

\section{Anti-SARS-COV-2 antibodies Amongst Asymptomatic Healthcare Workers and students of Tertiary Care hospital and Medical School in Pakistan}

Dr. Anila Jaleel, MBBS, Ph.D

Professor Biochemistry

Shalamar Medical \& Dental College, Lahore

Email: aneelajaleel@hotmail.com

Dr. Samar Asim

Sr Registrar

Pulmonology Department

Shalamar Medical \& Dental College, Lahore

Email: samaranvery@gmail.com

Dr. Kiran Namoos

Assistant Professor Biochemistry

Shalamar Medical \& Dental College, Lahore

Email: knamoos@hotmail.com

Dr. Sadaf Saleem Uppal

Associate professor Biochemistry

Shalamar Medical \& Dental College, Lahore

Email: $\underline{\text { sadafdr2010@ hotmail.com }}$

Dr. Shahila Jaleel

Associate Professor

Pathology Department

Shaikh Zaid Hospital Lahore

Email: Shahilajalil42@gmail.com

Dr. Waqas Shabbir

Assistant Professor Gastroenterology

LGH/PGMI/ Ameer-ud- din Medical College

Email: waqasshabbir197@ hotmail.com

Dr. Rukhshan Khursheed

Assistant Professor Biochemistry

Shalamar Medical \& Dental College, Lahore

Email: Rukhshan.khursheed@sihs.org.pk 


\begin{abstract}
Introduction: Coronavirus emerged as a pandemic in 2019 with the SARS COV 2 virus infecting people worldwide. Although PCR successfully detected symptomatic patients, asymptomatic patients remained undetected due to limitation of resources. The objective of the study was to determine the prevalence of $\operatorname{IgM}$ and IgG antibodies in the faculty, staff, and MBBS students in Medical school and tertiary care hospital, Pakistan.

Material and Methods: A cross-sectional study was conducted on 500 asymptomatic healthy subjects, from September to December 2020 in Biochemistry department Shalamar Medical and Dental College (SMDC). Rapid antibody test was used to determine the presence of IgM and $\operatorname{IgG}$ antibodies in the subjects. Those found IgM positive were validated by COVID 19 detection by Polymerase Chain Reaction.

Results: Anti-SARS-COV 2 antibodies was observed in $19.6 \%$ of 500 asymptomatic subjects. Significant reactive cases were identified in hospital staff $(27.5 \%)$ compared to hospital faculty (23.4\%), medical students $(21.4 \%)$, college faculty $(6.12 \%)$ followed by college staff $(3.06 \%)$. Significant reactive cases $(47.9 \%)$ were identified in middle age group i.e. between 31 to 45 years. $\mathrm{IgG}$ was more prevalent than $\operatorname{IgM}$ and $2 \%$ of the subjects showed coagulation disorders who were both IgG and IgM positive.

Conclusion: Prevalence of $19.6 \%$ of Anti-SARS-COV 2 antibodies was observed in asymptomatic subjects. Prevalence was more in males, people in the middle age group i.e. 31 to 45 years and in hospital staff and faculty.

Recommendations: Based on the study it is recommended that Rapid COVID 19- SRAC-2 antibody test, which is cost effective and rapid method may be used to detect the COVID 19 in developing countries with limited resources.
\end{abstract}

Key words: COVID 19, prevalence, Asymptomatic, Health Workers 


\section{Introduction}

The novel corona-virus SARS-CoV-2 causes the disease termed by the WHO as COVID -19 [1]. Covid-19 was declared a pandemic by the WHO in March 2020. Since trade between China and Pakistan was taking place, the virus spread despite borders being sealed. The virus spread to Pakistan from the Iranian border with the first case detected on 28th February 2020 in Karachi, Sind, after which it spread rapidly to other provinces. The peak of the first wave was seen in Pakistan during May and June at Eid-ul Fitar, i.e. the ceremony of Muslims after Ramadan. The second wave occurred in November 2020 when the weather turned cold in Pakistan. Seroprevalence of 36\% Anti-SARS-COV-2 antibodies was identified in residents of Karachi during the first wave by a study published by Samreen Zaidi et al., 2020. [2] The status given by National Coordination Committee (NCOC) Pakistan on Nov 15 showed 35903 confirmed cases out of which 28048 were active cases, 7160 deaths (2\%) and 323824 recovered cases (90.2\%) [3] The antibody prevalence depends on several epidemiological factors; in particular, the exposure to contagious cases (i.e., intensity and/or duration of exposure), the phase of the epidemic, immunological status and the diagnostic accuracy of the serological test (low sensitivity) [4].

The incidence and progression of SARS-CoV-2 is based on the interaction of the virus with the immune system of individuals. Infected persons with SARS-CoV-2 characteristically begin to produce antibodies like IgM and IgG that cover up the spikes of virus S protein and deactivate it. However, this course may be related with little immunity and prevent subjects from getting reinfected for a short time [4]. It is proposed that after the virus enters the cells, its antigen is accessible to MHC1 and MHC11, which are the main part of the anti-viral immunity of human body and later recognized by virus-precise cytotoxic $\mathrm{T}$ and $\mathrm{B}$ forms of lymphocytes. The SARSspecific IgG antibodies primarily are $\mathrm{S}$-specific (native spike) and $\mathrm{N}$ (native nucleocapsid) specific antibodies [5-7].

Testing of antibodies IgG and IgM of SARS- CoV- 2 in the blood of a patient is a fast, simple and sensitive method of identifying COVID- 19. Findings of IgM antibodies predict fresh exposure to SARS- CoV- 2, while the finding of COVID- 19 IgG predicts exposure to the virus in the past. It is therefore said that early detection of both antibodies may help in the identification and treatment of the COVID- 19 problem [4].

WHO recommended in March 2020 to do widespread testing to map the extent of disease, contact tracing, testing and identification of population at risk spots. Low and middle income countries with limited resources for widespread molecular testing were left with little options. Peeling at al, 2020 in his article recommended the use of rapid antibody testing of satisfactory performance [8]. Rapid antibody testing was used in Peru and China where large number of symptomatic contacts were tested by it which left very less subjects for molecular testing thus decreasing the burden on the heathcare system [9-10]. In February 10, 2020 WHO R \&D meeting was held in Geneva, Switzerland and leading health experts identified eight research and development priorities for COVID 19. The top priority list includes the research on rapid point of care testing for COVID 19 at the community level [11-12] (WHO, 2020; Pan American Health association, 2020).

Pakistan is also affected by the coronavirus pandemic. The government balance the health of the population with the economic survival of the people. While infected cases are increasing on daily 
basis, the mortality rate is $2 \%$ which is far less than the developed countries. Large number of people are either asymptomatic or have mild symptoms especially in low socioeconomic areas. However, these people can still transmit the infection. 44 infected documented cases occurred due to spread by asymptomatic individuals. There are different explanations to why this is the case. For example, one theory posits that Pakistanis may have better immunity, another supports the contention that the protocol of BCG vaccination to every child may protect them from infection or extensive use of antimalarial in our set up may be the reason for it [13-14]. The PCR based tests are also limited in Pakistan and cannot be done on the population due to limited resources, there is an urgent need for an accurate and rapid test method to quickly identify a large number of infected patients and asymptomatic carriers to prevent virus transmission and assure timely management of patients.

With this in mind the study was formulated to determine the sero-prevalence of antibodies in asymptomatic and COVID 19 recovered patients and to relate the positive antibodies with PCR testing in students, staff and faculty of private medical school and hospital in Lahore, Pakistan.

\section{Objectives of the study}

To determine the Anti-SRAS-COv-2 antibodies (IgG and IgM or IgG and IgM both) in healthy (asymptomatic or COVID 19 recovered) healthcare workers and students of private medical school and tertiary care hospital, Lahore, Pakistan

\section{Materials and Methods}

Prospective cross-sectional study was carried out at Biochemistry laboratory Shalamar Medical and Dental College (SMDC) from September 152020 to December 2020. 500 asymptomatic healthy subjects between the age range of 18 to 70 years and those who have recovered from COVID 19 (Past one month and PCR negative report) comprising of faculty, staff and medical students were recruited through convenient sampling technique. Informed consent was obtained and study was approved from the Institutional review board of Shalamar Medical and Dental college (IRB 218). Excluded patients were those patients suffering from symptoms of flu, fever, loss of taste/smell, cough, diarrhea or eye redness and those who were suffering from Covid 19 based on PCR positive result. Antibodies IgG and IgM were determined by rapid antibody finger prick test (Genrui- Novel Coronavirus (2019n-COV) IgG/IgM test kit) provided by Getz Pharma. The technique is based on lateral flow immunoassay (LFIA) that detects the antibodies within 15 minutes. The recombinant antigen (MK201027) is receptor binding domain of SARS- CoV- 2 Spike Protein, which is transient transfected in cell culture and purified by protein A affinity chromatography and size- exclusion chromatography. The design of the antigen was based on the published SARS- CoV- 2 sequence. One device sealed for each subject was provided which consisted of strip coated with antihuman $\operatorname{IgG}$, antihuman $\operatorname{IgM}$ and anti-rabbit IgG antibodies were immobilized at G,M and control lines respectively[15] . 


\section{Study Protocol:}

Faculty and staff of SMDC were approached by email advertisement and significance of the study was explained to them. The participation was made voluntary by providing consent form beforehand and by explaining the procedure to them that they have authority to take part in study. A brief history was taken regarding Covid -19 symptoms and those found asymptomatic were included in the study. Following the SOPs (CDC and WHO guidelines) for Covid -19 by the clinical laboratories, one drop of blood was drawn by finger prick under aseptic conditions by the lab technician and was tested for antibody test. The red line appears on control line which depicts that the test strip is valid. Red band is seen at area marked at M, indicating the subject is suffering from Covid 19. Those having band at $\mathrm{G}$ shows antibodies $\mathrm{IgG}$ are present and marks the previous exposure to Corona virus. Those having band at both $\mathrm{M}$ and $\mathrm{G}$ indicates that $\operatorname{IgG}$ and $\operatorname{IgM}$ antibodies are present in the subject and he/she needs to take precautions for one more week. Those found IgM positive were validated by PCR testing.

\section{Statistical analysis:}

SPSS version 22 was used to assess data. Data was expressed in frequency and Chi square

Test was applied. Mean deviation (MD) and standard deviation (SD) was determined and Student's T test was applied for quantitative variables.

\section{Results:}

Anti-SARS-COV-2 antibodies were assessed in 500 asymptomatic and COVID 19 recovered patients. No significant difference in age was identified between reactive and non-reactive cases. Asymptomatic reactive cases were 98 (8.6\%) and non- reactive cases were 402 (81.4\%) (figure1). History of contact with COVID 19 patients was observed in 274 (54.8\%) subjects. Out of 274 cases with contact history, 194 (70.8\%) were non- reactive and 80 (29.19\%) reactive. Similarly travel history was found in $169(33.8 \%)$ subjects of which $141(83.43 \%)$ were non- reactive and 28 $(16.5 \%)$ reactive cases (figure 2 ).

\section{FIGURE 1: AGE OF REACTIVE AND NON REACTIVE CASES}

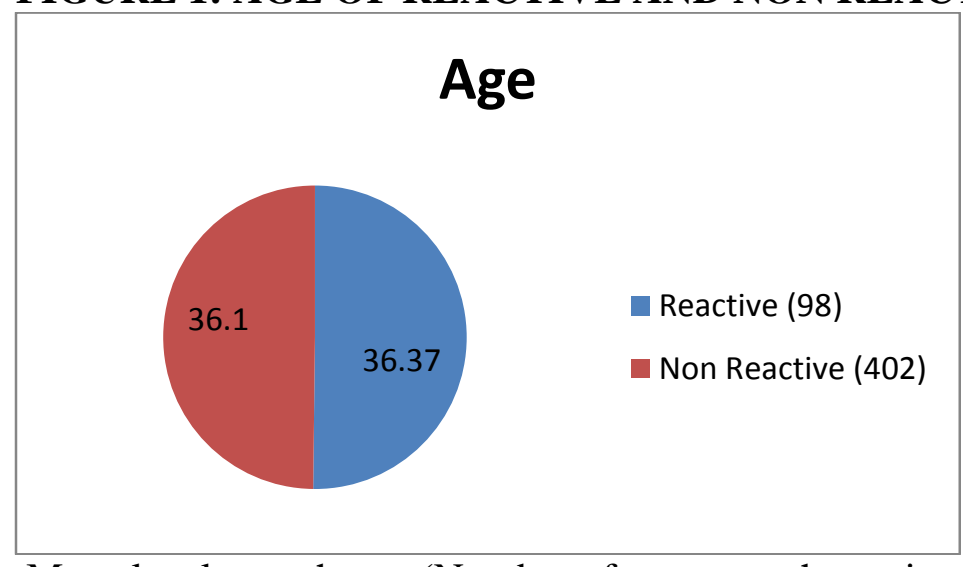

Mean levels are shown (Number of cases are shown in parenthesis) 
American Journal of Health, Medicine and Nursing Practice

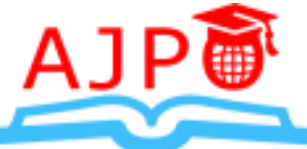

ISSN 2520-4017 (Online)

Vol.6, Issue 3, pp 25 - 38, 2021

www.ajpojournals.org

\section{FIGURE 2: CONTACT HISTORY AND TRAVEL HISTORY in REACTIVE AND NON REACTIVE CASES}

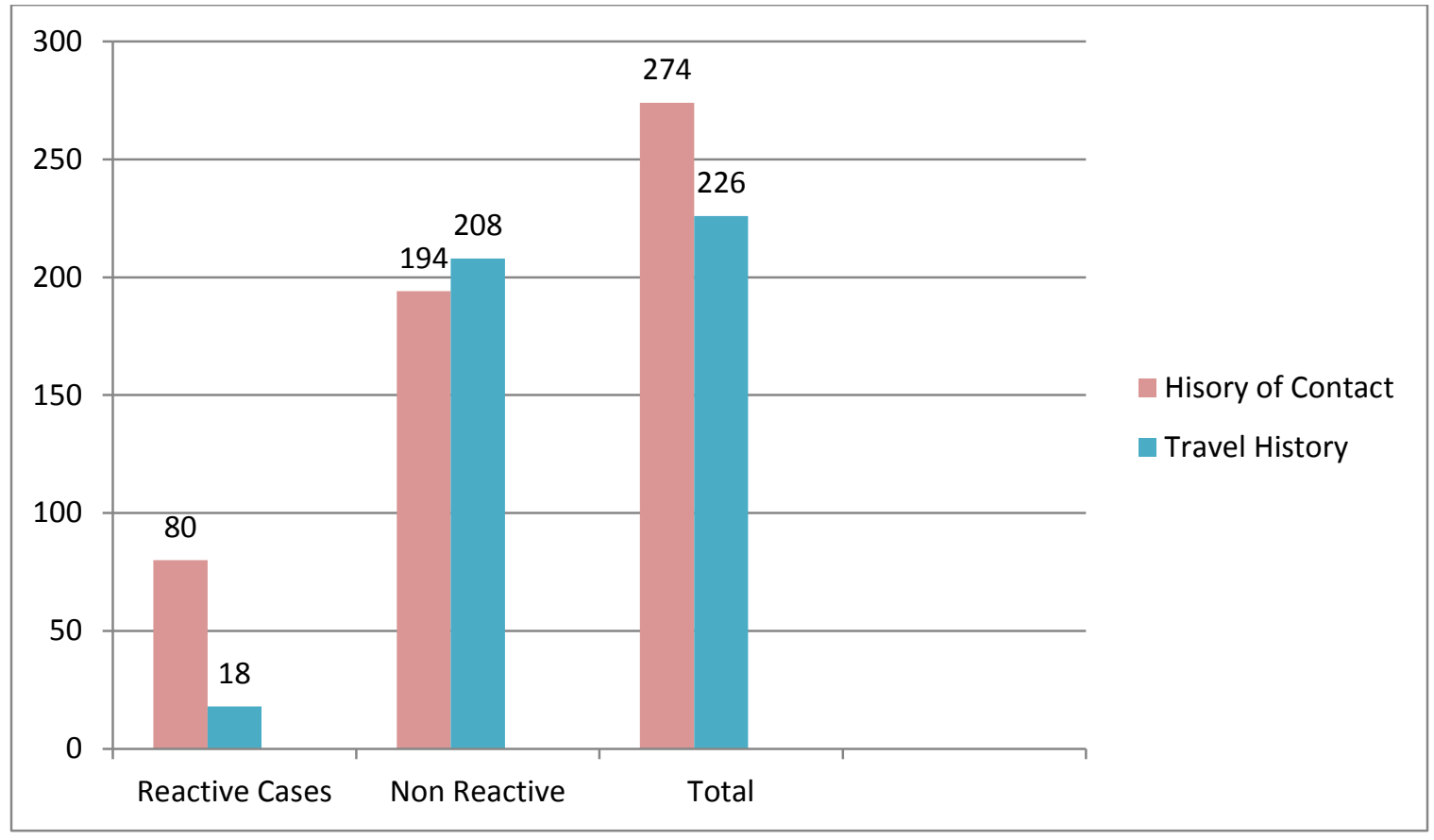

Table 1 shows the prevalence of anti-SARS antibodies according to gender and age groups. Males were more affected than females. Out of 57 reactive cases in males $56.1 \%$ were IgG positive, $14 \%$ IgM positive and $29.8 \%$ were both $\operatorname{IgG}$ and $\operatorname{IgM}$ positive. Similarly, in females $53.6 \%$ were $\operatorname{IgG}$, $14.6 \%$ IgM and $31.7 \%$ were positive in both. Significantly increased reactive cases (47.9\%) were identified in middle age group i.e. between 31 to 45 years while it was $27.5 \%$ and $24.5 \%$ in age groups of 18 to 30 years and 46-65 years respectively. Out of 98 reactive cases IgG levels were more $(55.1 \%)$ as compared to $\operatorname{IgM}(14.2 \%)$ and $\operatorname{IgM}$ and $\operatorname{IgG}$ both $(30.6 \%)$ respectively. There was significant difference in two groups ( $\mathrm{P}$ value is 0.07$)$. 
American Journal of Health, Medicine and Nursing Practice

ISSN 2520-4017 (Online)

Vol.6, Issue 3, pp 25 - 38, 2021

TABLE 1: NUMBER AND PERCENTAGE OF REACTIVE AND NON REACTIVE CASES ACCORDING TO GENDER AND AGE GROUPS

\begin{tabular}{|c|c|c|c|c|c|c|}
\hline Gender & $\begin{array}{l}\text { Total } \\
(\mathrm{n}=500)\end{array}$ & \multicolumn{3}{|c|}{$\begin{array}{l}\text { Reactive cases } \\
\quad(n=98)\end{array}$} & $\begin{array}{l}\text { Nonreactive } \\
(\mathrm{n}=402)\end{array}$ & case \\
\hline \multirow{3}{*}{ Male } & \multirow[t]{3}{*}{$262(52.2 \%)$} & \multicolumn{3}{|c|}{$57(58.1 \%)$} & \multicolumn{2}{|l|}{$205(51 \%)$} \\
\hline & & $\operatorname{IgM}$ & $\mathrm{IgG}$ & IgM and IgG & & \\
\hline & & $8(14 \%)$ & $32(56.1 \%)$ & \begin{tabular}{l|l|} 
& $17(29.8 \%)$ \\
\end{tabular} & & \\
\hline \multirow{3}{*}{ Female } & \multirow[t]{3}{*}{$238(47.8 \%)$} & \multicolumn{3}{|c|}{$41(41.8 \%)$} & \multirow{3}{*}{\multicolumn{2}{|c|}{$197(49 \%)$}} \\
\hline & & $\operatorname{IgM}$ & $\mathrm{IgG}$ & IgM and IgG & & \\
\hline & & $6(14.6 \%$ & $22(53.6 \%)$ & $13(31.7 \%)$ & & \\
\hline Age Groups & $\begin{array}{l}\text { Total } \\
(\mathrm{n}=500)\end{array}$ & \multicolumn{3}{|c|}{$\begin{array}{c}\text { Reactive cases } \\
(\mathrm{n}=98)\end{array}$} & $\begin{array}{l}\text { Nonreactive } \\
\text { Cases } \\
(n=402)\end{array}$ & $\begin{array}{l}\mathrm{P} \\
\text { value }\end{array}$ \\
\hline 18 to 30 years & $163(32.6 \%)$ & \multicolumn{3}{|c|}{$27(27.5 \%)$} & $136(33.9 \%)$ & \multirow[t]{4}{*}{0.07} \\
\hline 31 to 45 years & $227(45.4 \%)$ & \multicolumn{3}{|c|}{$47(47.9 \%)$} & $180(44.7 \%)$ & \\
\hline \multirow[t]{4}{*}{46 to 65 years } & $110(22 \%)$ & \multicolumn{3}{|c|}{$24(24.5 \%)$} & \multirow[t]{2}{*}{$86(24.5 \%)$} & \\
\hline & & $\mathrm{IgG}$ & $\operatorname{IgM}$ & IgG and IgM & & \\
\hline & & 54 & 14 & 30 & & \\
\hline & & $55.1 \%$ & $14.2 \%$ & $30.6 \%$ & & \\
\hline
\end{tabular}

Table 2 shows distribution by profession. Most of the reactive cases were identified in hospital staff $27.5 \%$ compared to hospital faculty $(23.4 \%)$, medical students $21.4 \%$. college faculty $6.12 \%$ followed by college staff $3.06 \%$. Chi square was applied which showed significance ( $\mathrm{P}$ value $=0.000)$. 
American Journal of Health, Medicine and Nursing Practice

ISSN 2520-4017 (Online)

Vol.6, Issue 3, pp 25 - 38, 2021

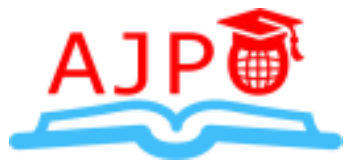

www.ajpojournals.org

\section{TABLE 2: NUMBER AND PERCENTAGE OF REACTIVE AND NON REACTIVE CASES ACCORDING TO PROFESSION}

\begin{tabular}{|c|c|c|c|c|}
\hline Groups & Total (500) & Reactive cases (98) & Nonreactive Cases (402) & $\mathrm{P}$ value \\
\hline College Faculty & $45(9 \%)$ & $6(13.3 \%)$ & $39(86.6 \%)$ & \multirow{6}{*}{0.000} \\
\hline College Staff & $76(15.2 \%)$ & $3(3.9 \%)$ & $73(96.1 \%)$ & \\
\hline Hospital Faculty & $118(23.6 \%)$ & $23(19.4 \%)$ & $95(80.5 \%)$ & \\
\hline Hospital Staff & $55(11 \%)$ & $27(49.1 \%)$ & $28(51 \%)$ & \\
\hline MBBS Students & $131(26.2 \%)$ & $21(16.0 \%)$ & $110(83.96 \%)$ & \\
\hline Others & $75(15 \%)$ & $18(24 \%)$ & $57(23.8 \%)$ & \\
\hline
\end{tabular}

Table 3 shows IgM, IgG and IgG and IgM levels both in reactive cases by profession. It was observed that IgG levels were more in all groups compared with IgM and both levels. Similarly frequency of subjects with IgG was more in hospital staff followed by hospital faculty. Out of 27 reactive cases of hospital staff $14(51.8 \%)$ were IgG positive, $3(11.1 \%)$ IgM and $10(37 \%)$ with both $\mathrm{IgM}$ and $\mathrm{IgG}$ positive. Out of 23 reactive cases of hospital faculty 10 (43.7\%) were $\mathrm{IgG}, 11$ (47.8) IgM and IgG both and 2(8.5\%) IgM positive. $26.2 \%$ of medical students were also reactive and least affected was the basic sciences college faculty.

\section{TABLE 3: NUMBER AND PERCENTAGE OF ANTIBODIES IN REACTIVE CASES ACCORDING TO PROFESSION}

\begin{tabular}{|l|l|l|l|l|}
\hline Groups & $\begin{array}{l}\text { Reactive } \\
\text { cases (98) }\end{array}$ & IgM & IgG & IgM and IgG both \\
\hline College Faculty & 6 & $1(16.6 \%)$ & $5(83.3 \%)$ & Nil \\
\hline College Staff & 3 & $1(33.3 \%)$ & $1(33.3 \%)$ & $1(33.3 \%)$ \\
\hline Hospital Faculty & 23 & $2(8.69 \%)$ & $10(43.5 \%)$ & $11(47.8 \%)$ \\
\hline Hospital Staff & $\mathbf{2 7}$ & $\mathbf{3 ( 1 1 . 1 \% )}$ & $\mathbf{1 4 ( 5 1 . 8 \% )}$ & $\mathbf{1 0}(\mathbf{3 7 . 0 \% )}$ \\
\hline MBBS Students & 21 & $5(23.8 \%)$ & $11(52.3 \%)$ & $5(23.8 \%)$ \\
\hline Others & 18 & $2(11.1 \%)$ & $13(72.2 \%)$ & $3(16.6 \%)$ \\
\hline
\end{tabular}

Table 4 shows the antibody status in asymptomatic subjects who recovered from COVID 19 three months back and those who had no symptoms of COVID 19 but were IgM, IgG or both positive. 40 asymptomatic subjects with no COVID 19 history tested positive for IgG, 11 for IgM and 18 both IgG and IgM. Similarly, 14, 3 and 12 subjects who suffered COVID 19 three month back exhibit IgG, IgM and both antibodies respectively in blood (Table 4). Those with IgM positive were PCR tested and 12 out of 14 were found positive i.e. suffering from COVID 19. 
American Journal of Health, Medicine and Nursing Practice

TABLE 4: ANTIBODIES IN ASYMPTOMATIC SUBJECTS WITH AND WITHOUT COVID 19 HISTORY

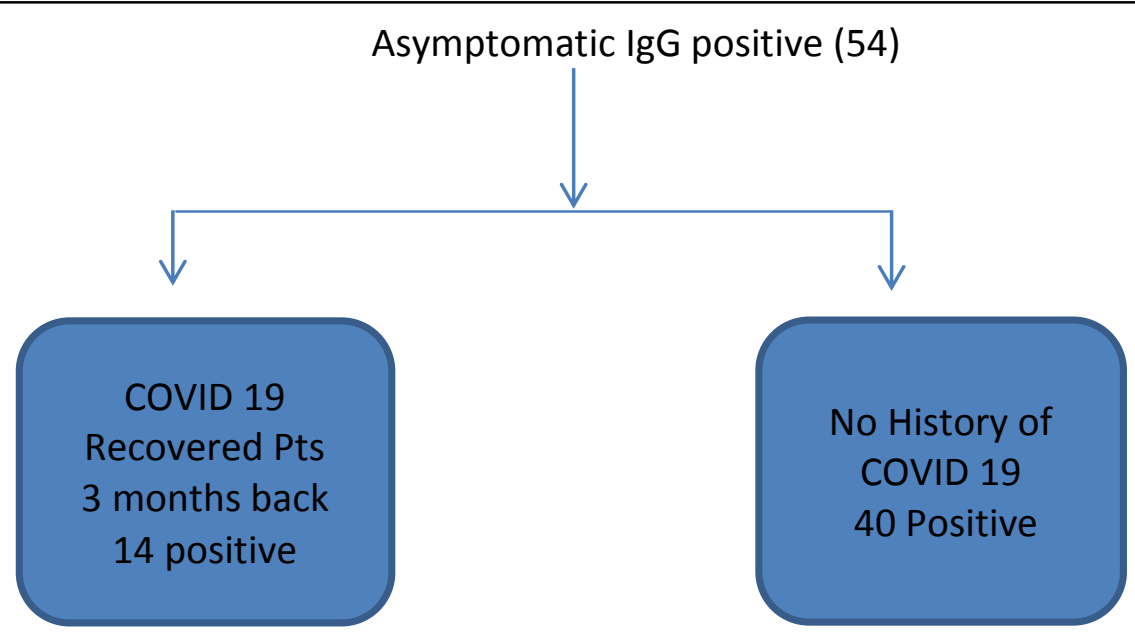

Asymptomatic IgM positive (14)

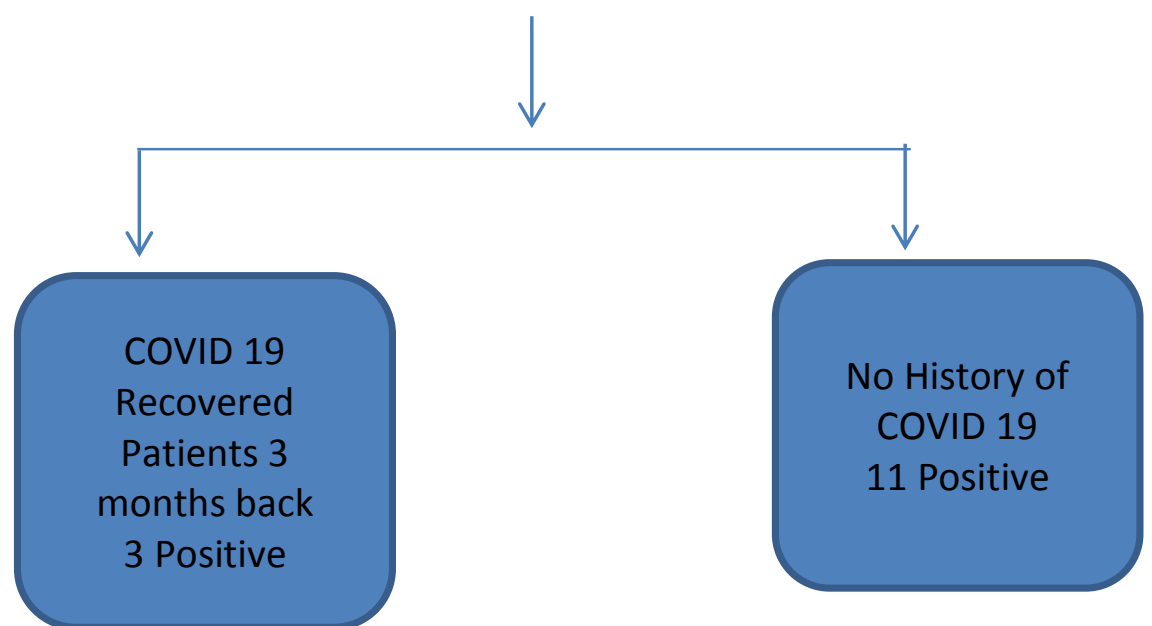

Asymptomatic IgM and IgG positive (30)
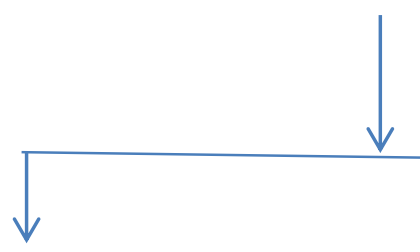

COVID 19

Recovered

patients

3 months back

12 positive

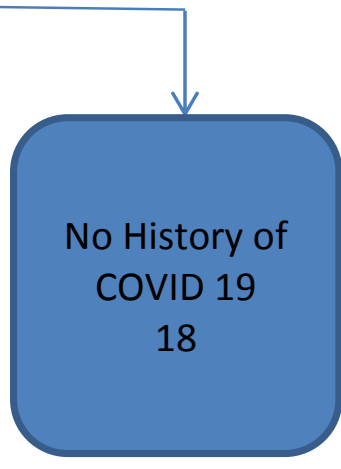




\section{Discussion}

The study determines the Anti-SARS-COV-2 antibodies amongst the faculty, staff and students of Shalamar Medical and Dental College and hospital. Out of 500 asymptomatic subjects, 98 (19.6\%) were found reactive while 402 were non-reactive (814\%). Reactive cases in males were significantly higher than females. Study by Giefing-Kroll et al., (2015) reported that response of immune system, sex hormones and genetic factors results in men being more prone to getting the infection and with more severity of symptoms than women [16]. Another study reported that due to the presence of $\mathrm{X}$ chromosome, women have a powerful immune system and give late response to infection as compared to men [17].

History of contact with COVID 19 patients was observed in 274 (54.8\%) and travel history in 169 (33.8\%) subjects. Out of 274 cases of contact history 80 (29.19\%) were reactive and out of 169 with travel history $28(16.5 \%)$ were reactive cases. Analysis of a study found that close contacts to confirm COVID-19 cases revealed a relatively short infectious period of COVID-19 and a higher transmission risk around the time of symptom onset of the index case, followed by a lower transmission risk at the later stage of disease [18].

Age difference in reactive and non- reactive subjects was non- significant in the study. However majority reactive cases $(47.9 \%)$ were found in middle aged group i.e. 31 to 45 years. Amongst reactive cases $\operatorname{IgG}$ was most prevalent $(55.1 \%)$ followed by both IgG and IGM (30.6\%) and IgM (14.2\%). Amongst IgG positive cases 14 were those who had recovered from COVID 19 three months back while 40 positive cases were seen in subjects without any COVID 19 history. Similar pattern was seen in $\operatorname{IgM}$ positive and $\operatorname{IgM}$ and $\operatorname{IgG}$ positive cases. These point out those asymptomatic subjects had experienced COVID 19 without any significant symptoms and were the agent in spreading the infection unknowingly. It was noteworthy that those subjects who recovered from COVID 19 three to four months ago but were still experiencing loss of sense of taste and smell or breathlessness on exertion, showed IgM and IgG positive in their blood. It points that either the virus is still residing inside the body and is active or their duration of illness is prolonged and they are still in recovery phase. Zhou et al., 2020 showed in his study that IgM antibodies in serum of patients lasted up to 3-4 months till $7^{\text {th }}$ month and IgG remained high in the sera collected at 4th month [19].

Samreen Zaidi et al., showed sero-prevalence rate of $36 \%$ during first wave of COVID 19 in Karachi and predicts that if it continues to prevail with such intensity than there is great chance of acquiring herd immunity and chance of second wave will be less [2]. However our study showed that IgG was positive in those COVID 19 recovered individuals who suffered from moderate to severe attack and did not appear in mild cases. Study by Wang and Couleages, (2020) showed that a number of patients remain RNA positive despite high concentration of antibodies, however elevated IgM levels in blood are correlated with poor outcome in patients and high IgG levels are found in patients who suffered severe COVID 19 pneumonia which supports our data [20].

Li et al., (2020) observed in his study that Corona virus use ACE2 protein to enter into the cells. Gene related to ACE2 in human is related with different expressions of ACE2 and may be linked with COVID-19 infection. The level of ACE2 is higher in male and rises with age [4]. Another study reported that co morbidities are more prevalent with increasing age which may be one of the factors for prevalence of disease in them [21]. Moreover the cause of difference in 
occurrence of COVID 19 in different age groups is reported to be mainly due to difference in immune system, inflammasome activity, glycation, epigenome activity and aging [22].

Similarly reactive cases were highest in hospital staff (49.1\%) followed by hospital faculty $(19.1 \%)$ i.e. clinicians. $16.1 \%$ of medical students were also reactive and least affected was basic sciences college faculty. It was observed that IgG levels were more in all groups compared with IgM and both levels. Similarly frequency of subjects with IgG was more in hospital staff $(51.8 \%)$ followed by hospital faculty $(43.7 \%)$. On the other hand the frequency of IgM was $11.1 \%$ in hospital staff and $47.8 \%$ in hospital faculty. It may be due to greater exposure of the hospital staff and faculty to COVID 19 patients as well as lack of provision of appropriate protective equipment to medical /paramedical staff in our setting. Study by Sogiu et al., (2020) found that medical doctors presented the higher percentage of IgG (14.8\%), whereas other categories of medical profession showed the higher percentages of $\operatorname{IgM}(26.1 \%)$. It is stated that production of $\operatorname{IgM}$ is usually during the acute stage of the infection, tracked by IgG represent immunological memory [23]. Detection of antibodies IgG and IgM against the virus SARS- CoV- 2 has potential value for assessing the severity and diagnosis of cornovirus-19 [24]. Levels of IgG antibodies served as an indicator for the occurrence of antibodies which have an ability to neutralize SARS-CoV-2 in-vitro [23]. The occurrence of $\operatorname{IgM}$ in the serum is related with an acute phase of the infections; in particular, the diagnosis of $\operatorname{IgM}$ is also based to assess the immunological response against a virus to determine a fresh interaction between a virus and the host. However, the kinetics of antibody is complex: some patients could not display IgM in the acute infection or, sometimes, can express a combination of $\mathrm{IgG}$ and IgM [4]. However, the antibody response kinetics in SARS-CoV-2 infection is largely unknown, as well as its clinical value [24].

In SARS-CoV infection, the serum level of anti-viral IgM drops in a few months whereas the titers of antiviral IgG antibody can continue for months. In SARS-CoV-2, the S and N proteins are the immunogenic antigens. Antibodies against the $\mathrm{N}$ protein are appear first and serve as an early predictor of virus exposure, whereas antibodies against the $\mathrm{S}$ protein lately formed, bind to the viral envelope. Studies showed that the convalescing serum contains antibodies which neutralize SARS-CoV-2 in lab. It is concluded that antibody IgG against the S protein of SARS-CoV-2 is both an indicator for viral exposure and pointer of recovery $[25,26]$.

\section{Conclusion}

- Prevalence rate of $19.6 \%$ was obtained in asymptomatic subjects. Those who had no history of COVID 19 but were reactive may be serving as the agents in spreading the infection unknowingly to healthy population.

- It was more prevalent in males, middle age group i.e.31 to 45 years and in hospital staff and faculty

- IgG levels in asymptomatic subjects shows that they have acquired immunity against COVID 19 virus

- It may be a cost effective method to evaluate the immune status of asymptomatic subjects in developing countries where resources are limited. 
American Journal of Health, Medicine and Nursing Practice

ISSN 2520-4017 (Online)

Vol.6, Issue 3, pp 25 - 38, 2021

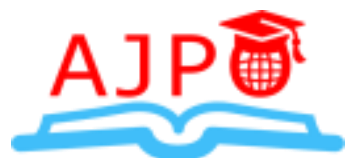

www.ajpojournals.org

\section{Recommendations}

Based on the study it is recommended that Rapid COVID 19- SRAC-2 antibody test, which is cost effective and rapid method may be used to detect the COVID 19 in developing countries with limited resources. The study may be extended in future to COVID 19 patients with comorbidities and vaccinated subjects

\section{REFERENCES}

1. World Health Organization. (2020). World Health Organization coronavirus disease 2019 (COVID-19) situation report.

2. Zaidi, S., Rizwan, F., Riaz, Q., Siddiqui, A., Khawaja, S., Imam, M., ... \& Shamsi, T. (2020). Seroprevalence of anti-SARS-CoV-2 antibodies in residents of Karachi-challenges in acquiring herd immunity for COVID 19. Journal of public health (Oxford, England).

3. Abid, K., Bari, Y. A., Younas, M., Tahir Javaid, S., \& Imran, A. (2020). <? covid19?> Progress of COVID-19 Epidemic in Pakistan. Asia Pacific Journal of Public Health, 32(4), 154-156.

4. Li, Z., Yi, Y., Luo, X., Xiong, N., Liu, Y., Li, S., ... \& Ye, F. (2020). Development and clinical application of a rapid IgM- IgG combined antibody test for SARS- CoV- 2 infection diagnosis. Journal of medical virology, 92(9), 1518-1524.

5. Chen, Y. M. A., Liang, S. Y., Shih, Y. P., Chen, C. Y., Lee, Y. M., Chang, L., ... \& Chu, D. C. (2006). Epidemiological and genetic correlates of severe acute respiratory syndrome coronavirus infection in the hospital with the highest nosocomial infection rate in Taiwan in 2003. Journal of clinical microbiology, 44(2), 359-365.

6. Liu, J., Liao, X., Qian, S., Yuan, J., Wang, F., Liu, Y., ... \& Zhang, Z. (2020).

Community transmission of severe acute respiratory syndrome coronavirus 2 , Shenzhen, China, 2020. Emerging infectious diseases, 26(6), 1320.

7. De Wit, E., Van Doremalen, N., Falzarano, D., \& Munster, V. J. (2016). SARS and MERS: recent insights into emerging coronaviruses. Nature Reviews Microbiology, 14(8), 523.

8. Peeling, R. W., Wedderburn, C. J., Garcia, P. J., Boeras, D., Fongwen, N., Nkengasong, J., ... \& Heymann, D. L. (2020). Serology testing in the COVID-19 pandemic response. The Lancet Infectious Diseases. 
American Journal of Health, Medicine and Nursing Practice

ISSN 2520-4017 (Online)

Vol.6, Issue 3, pp 25 - 38, 2021

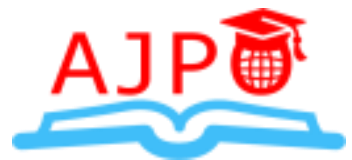

www.ajpojournals.org

9. Zheng, S., Fan, J., Yu, F., Feng, B., Lou, B., Zou, Q., ... \& Liang, T. (2020). Viral load dynamics and disease severity in patients infected with SARS-CoV-2 in Zhejiang province, China, January-March 2020: retrospective cohort study. Bmj, 369.

10. Zheng, J. (2020). SARS-CoV-2: an emerging coronavirus that causes a global threat. International journal of biological sciences, 16(10), 1678.

11. World Health Organization. (2020). Advice on the use of point-of-care immunodiagnostic tests for COVID-19: scientific brief, 8 April 2020 (No. WHO/2019nCoV/Sci_Brief/POC_immunodiagnostics/2020.1). World Health Organization.

12. Pan American Health Organization. Advice on the use of point-of-care immunodiagnostic tests for COVID-19. April 8, 2020. https://covid19evidence.paho.org/handle/20.500.12663/989.

13. Abid, K., Bari, Y. A., Younas, M., Tahir Javaid, S., \& Imran, A. (2020). <? covid19?> Progress of COVID-19 Epidemic in Pakistan. Asia Pacific Journal of Public Health, 32(4), 154-156.

14. Walk, J., de Bree, L. C. J., Graumans, W., Stoter, R., van Gemert, G. J., van de VegteBolmer, M., ... \& Sauerwein, R. W. (2019). Outcomes of controlled human malaria infection after BCG vaccination. Nature communications, 10(1), 1-8.

15. Petherick, A. (2020). Developing antibody tests for SARS-CoV-2. The Lancet, 395(10230), 1101-1102.

16. Giefing- Kröll, C., Berger, P., Lepperdinger, G., \& Grubeck- Loebenstein, B. (2015). How sex and age affect immune responses, susceptibility to infections, and response to vaccination. Aging cell, 14(3), 309-321.

17. Conti, P., \& Younes, A. (2020). Coronavirus COV-19/SARS-CoV-2 affects women less than men: clinical response to viral infection. J Biol Regul Homeost Agents, 34(2), 339-343. 18. Zhou, C., Bu, G., Sun, Y., Ren, C., Qu, M., Gao, Y., ... \& Liu, Y. (2020). Evaluation of serum $\operatorname{IgM}$ and $\mathrm{IgG}$ antibodies in COVID- 19 patients by enzyme linked immunosorbent assay. Journal of Medical Virology. 
19. Zhou, C., Bu, G., Sun, Y., Ren, C., Qu, M., Gao, Y., ... \& Liu, Y. (2020). Evaluation of serum IgM and IgG antibodies in COVID- 19 patients by enzyme linked immunosorbent assay. Journal of Medical Virology.

20. Wang, T., Chen, R., Liu, C., Liang, W., Guan, W., Tang, R., ... \& Li, S. (2020). Attention should be paid to venous thromboembolism prophylaxis in the management of COVID19. The Lancet Haematology, 7(5), e362-e363.

21. Raoult, D., Zumla, A., Locatelli, F., Ippolito, G., \& Kroemer, G. (2020). Coronavirus infections: Epidemiological, clinical and immunological features and hypotheses. Cell stress, 4(4), 66.

22. Mueller, A. L., McNamara, M. S., \& Sinclair, D. A. (2020). Why does COVID-19 disproportionately affect older people?. Aging (Albany NY), 12(10), 9959..

23. Sotgiu, G., Barassi, A., Miozzo, M., Saderi, L., Piana, A., Orfeo, N., ... \& Centanni, S. (2020). SARS-CoV-2 specific serological pattern in healthcare workers of an Italian COVID19 forefront hospital. BMC Pulmonary Medicine, 20(1), 1-6.

24. Hou, H., Wang, T., Zhang, B., Luo, Y., Mao, L., Wang, F., ... \& Sun, Z. (2020). Detection of $\operatorname{IgM}$ and $\operatorname{IgG}$ antibodies in patients with coronavirus disease 2019. Clinical \& translational immunology, 9(5), e1136.

25. Zhou, P., Yang, X. L., Wang, X. G., Hu, B., Zhang, L., Zhang, W., ... \& Shi, Z. L. (2020). A pneumonia outbreak associated with a new coronavirus of probable bat origin. nature, 579(7798), 270-273.

26. Walls, A. C., Park, Y. J., Tortorici, M. A., Wall, A., McGuire, A. T., \& Veesler, D. (2020). Structure, function, and antigenicity of the SARS-CoV-2 spike glycoprotein. Cell, 181(2), 281-292. 